Original Research Article

\title{
Implementing standardised rhodes index to measure the efficacy of ginger extract (Zingiber officinale) in pregnancy induced nausea and vomiting
}

\author{
Asha P. Dass ${ }^{1 *}$, Priyadarshini Deodurg ${ }^{1}$, Sandhiya Rajappan ${ }^{2}$
}

\begin{abstract}
${ }^{1}$ Department of Pharmacology, Gulbarga Institute of Medical Sciences, Gulbarga, Karnataka, India

${ }^{2}$ CHRI, Chennai, Tamilnadu, India
\end{abstract}

Received: 25 April 2017

Accepted: 27 June 2017

*Correspondence to:

Dr. Asha P. Dass,

Email: ashapdass@gmail.com

Copyright: (c) the author(s), publisher and licensee Medip Academy. This is an openaccess article distributed under the terms of the Creative Commons Attribution NonCommercial License, which permits unrestricted noncommercial use, distribution, and reproduction in any medium, provided the original work is properly cited.

\begin{abstract}
Background: Although nausea and vomiting are natural signs of pregnancy affecting about half the pregnant women during their first trimester of pregnancy, it is unpleasant and difficult symptom to deal with. Considering the fact that medication during pregnancy is not advised, we decided to study the efficacy of a natural product to control nausea and vomiting during early pregnancy. Our study was directed to estimate the efficacy of ginger extract (Zingiber officinale) in pregnancy induced nausea and vomiting.

Methods: A total of 30 women with pregnancy of 4-16 weeks, suffering from nausea and vomiting were included in this study $(n=30)$. Subjects were given ginger extract $250 \mathrm{mg}$, to be taken 3 times a day half an hour before food for 1 week. Severity of vomiting was assessed by Rhodes Index of Nausea and Vomiting by the patients. Baseline scores were compared with the score at the end of 7 day. The findings were analysed statistically.

Results: Effect with the ginger extract in pregnancy induced nausea and vomiting was assessed at the end of treatment (day 7) and compared with the baseline values. Four patients reported symptoms of heartburn. Otherwise, there were no other reports of any adverse effects. The results showed significance ( $p$ $<0.005)$.

Conclusions: Ginger extract (Zingiber officinale) helps in reducing severity and frequency of pregnancy induced nausea and vomiting. Therefore, we conclude that ginger extract can be used for mild to moderate nausea and vomiting induced by pregnancy during first trimester.
\end{abstract}

Keywords: Ginger extract, Pregnancy induced nausea and vomiting, Rhodes Index, Zingiber officinale

\section{INTRODUCTION}

Nausea and vomiting is a commonly encountered problem by women in early pregnancy. Nausea is prevalent in about 50 to $80 \%$ of pregnant women, and vomiting and retching in about $50 \% .^{1}$ Retching or dry heaving, without expulsion of the stomach's contents is a distinct symptom that is increasingly measured separately to vomiting and nausea. The misnomer 'morning sickness', which is colloquially used to describe nausea, vomiting and retching of pregnancy, contradicts the fact that symptoms can occur at any part of the day. Nausea, vomiting and retching are experienced most often in the first trimester, between six and 12 weeks, but this can continue to 20 weeks and persists after this time in up to $20 \%$ of women. ${ }^{1-5}$ Hyperemesis gravidarum, which is characterized by severe and persistent vomiting, is less common, affecting between $0.30 \%$ and $3 \%$ of pregnant women. ${ }^{6,7}$

Ketosis is also commonly included as a consequence of hyperemesis gravidarum. ${ }^{8,9}$ However, inpatient hospitalisation is not included in the definition of hyperemesis gravidarum because occasionally, it may be 
alleviated or controlled by outpatient interventions. ${ }^{10}$ Within the operational definitions of hyperemesis gravidarum, there is generally a focus on the effects of the vomiting like dehydration, ketosis and weight loss. It is important to exclude pathological causes of nausea and vomiting before concluding that it is specific to pregnancy.

Conditions such as peptic ulcers, cholecystitis, gastroenteritis, appendicitis, hepatitis, genito-urinary (e.g. pyelonephritis), metabolic and neurological disorders should be ruled out. ${ }^{11-13}$

The main objective of the study was to estimate the efficacy of ginger extract (Zingiber officinale) in pregnancy induced nausea and vomiting.

\section{METHODS}

Study population were women attending the antenatal clinic.

\section{Inclusion criteria}

Women between 4 and 16 weeks of gestation, with pregnancy confirmed by urine pregnancy test and with nausea or vomiting.

\section{Exclusion criteria}

Signs of clinical dehydration, known allergy to ginger, Gallstones or any other disease of the gallbladder, Diabetes or on any drugs to control blood sugar levels, cardiovascular disorders and any factor affecting clotting time.

Table 1: Rhodes index of nausea, vomiting and retching.

\begin{tabular}{|c|c|c|c|c|c|c|}
\hline \multicolumn{7}{|c|}{ Patient Initial: } \\
\hline \multicolumn{7}{|c|}{ Date: } \\
\hline \multicolumn{7}{|c|}{ Day of week: } \\
\hline \multicolumn{7}{|c|}{ Time of day: } \\
\hline \multicolumn{2}{|c|}{ **Questionnaire given to patient } & \multicolumn{5}{|c|}{ Scoring provided according to Rhodes Index } \\
\hline \multirow[t]{3}{*}{1.} & In the last 12 hours, I threw up __ times. & 7 or More & $5-6$ & $3-4$ & $1-2$ & I did not \\
\hline & & & & & & throw up \\
\hline & score & 4 & 3 & 2 & 1 & 0 \\
\hline \multirow[t]{3}{*}{2 . } & $\begin{array}{l}\text { In the last } 12 \text { hours, from retching and dry heaves, I } \\
\text { have }\end{array}$ & No & Mild & Moderate & Great & Severe \\
\hline & \multicolumn{6}{|l|}{ felt ___ distress. } \\
\hline & score & 0 & 1 & 2 & 3 & 4 \\
\hline \multirow[t]{3}{*}{3.} & $\begin{array}{l}\text { In the last } 12 \text { hours, from vomiting or throwing up, I } \\
\text { have }\end{array}$ & Severe & Great & Moderate & Mild & No \\
\hline & \multicolumn{6}{|l|}{ felt ___ distress. } \\
\hline & score & 4 & 3 & 2 & 1 & 0 \\
\hline \multirow[t]{3}{*}{4.} & In the last 12 hours, I have felt nauseated or sick to my & Not at all & $\begin{array}{l}1 \text { hour } \\
\text { or }\end{array}$ & $2-3$ hours & $\begin{array}{l}4-6 \\
\text { hours }\end{array}$ & $\begin{array}{l}\text { More } \\
\text { than } 6\end{array}$ \\
\hline & stomach. & & less & & & hours \\
\hline & Score & 0 & 1 & 2 & 3 & 4 \\
\hline \multirow[t]{3}{*}{5} & $\begin{array}{l}\text { In the last } 12 \text { hours, from nausea/sickness to my } \\
\text { stomach, }\end{array}$ & No & Mild & Moderate & Great & Severe \\
\hline & \multicolumn{6}{|l|}{ I have felt ___ distress. } \\
\hline & score & 0 & 1 & 2 & 3 & 4 \\
\hline \multirow[b]{2}{*}{6.} & \multirow[b]{2}{*}{$\begin{array}{l}\text { In the last } 12 \text { hours, each time I threw up, I produced a } \\
\text { amount. }\end{array}$} & Very large & Large & Moderate & Small & I did not \\
\hline & & $\begin{array}{l}(3 \text { cups or } \\
\text { more })\end{array}$ & $\begin{array}{l}(2-3 \\
\text { cups })\end{array}$ & $\begin{array}{l}(1 / 2-2 \\
\text { cups })\end{array}$ & $\begin{array}{l}\text { (up to } \\
1 / 2 \text { cup) }\end{array}$ & throw up \\
\hline & score & 4 & 3 & 2 & 1 & 0 \\
\hline \multirow[t]{3}{*}{7.} & In the last 12 hours, I have felt nauseated or sick to my & 7 or more & $5-6$ & $3-4$ & $1-2$ & No \\
\hline & \multicolumn{6}{|l|}{ stomach ___ times. } \\
\hline & score & 4 & 3 & 2 & 1 & 0 \\
\hline 8. & $\begin{array}{l}\text { In the last } 12 \text { hours, I have had periods of retching or } \\
\text { dry }\end{array}$ & No & $1-2$ & $3-4$ & $5-6$ & 7 or more \\
\hline \multicolumn{7}{|c|}{ heaves without bringing anything up __ times. } \\
\hline & score & 0 & 1 & 2 & 3 & 4 \\
\hline
\end{tabular}

**Patient marked the box in each row that most clearly corresponds to her experience. Scoring done after completion of questionnaire 
Women who meet the eligibility criteria were enrolled into the study. Demographic information, general history and history of nausea and vomiting were taken. Health status assessment was conducted for each woman before initiation of the study. They were then requested to fill the Rhodes Index of Nausea and Vomiting Form 2.

The frequency, severity of vomiting and the approximate volume of the vomitus was recorded. They were then asked to complete the Rhodes Index of Nausea and Vomiting Form 2 for 3 days as a baseline before administering the extract. The Rhodes scale is a 5-point Likert scale ranging from 0 to 12 , with larger scores indicating more symptoms. A major issue in interpreting and comparing studies on the management of NVP has been the use of numerous different methods to qualify and quantify nausea, vomiting and related symptoms. Different researchers have arbitrarily defined NVP as "mild", "moderate" or "severe" without clear quantitative definitions or biological logic. Often the assessments have been retrospective. In some cases end points were measured dichotomously as success/failure or as percentage preferring one drug over the other (in crossover studies). While these approaches may be reasonable in randomised control trials (RCTs), assuming that all arms of the studies are evaluated similarly, the clinical interpretation of arbitrary endpoints and comparison between studies becomes difficult, if not impossible.

Rhodes Index is a standard, validated tool that will allow comparison among studies to assess nausea and vomiting in pregnancy. It separately scores, as categorical variables, the number of vomiting episodes per day, the size of the vomiting, the degree and length of nausea and retching, as well as the distress associated with the condition (Table 1).

The questionnaire can be administered once or twice a day and, in addition to an overall score, one can report separately on the frequency and changes in nausea, vomiting, retching and stress. ${ }^{7}$ Ginger extract was prepared by Sami Labs (Bangalore) with a certificate of analysis issued that ensures the products were standardized and quality controlled. The study subjects were given the required quantity of ginger extract and instructed to take $250 \mathrm{mg}, 3$ times a day half an hour before food for 1 week. At the end of 1 week the Rhodes Index of Nausea and Vomiting Form 2 was reassessed, and any change in the frequency of nausea and vomiting was recorded at the end of 1 week. Secondary outcomes included the occurrence of any side effects.

\section{Statistical analysis}

Statistical data was analysed using SPSS Software Version 18. The hypothesis was tested using paired ' $t$ ' test to assess the change from baseline. Demographic data are described using Mean and Standard Deviation.

\section{RESULTS}

A total of 30 women with pregnancy of 4-16 weeks, suffering from nausea and vomiting were included in this study.

The mean age was 22.17 years (SD 2.230) and means duration of pregnancy was 11.43 weeks (SD 1.716). The Rhodes Index scores at baseline and from days 1 to 7 are shown in Table 2.

Table 2: Rhodes Index Score at baseline and during treatment with ginger extract.

\begin{tabular}{|llll|l|}
\hline $\begin{array}{l}\text { Day of } \\
\text { assessment }\end{array}$ & $\begin{array}{l}\text { Mini- } \\
\text { mum } \\
\text { score }\end{array}$ & $\begin{array}{l}\text { Maxi- } \\
\text { mum } \\
\text { score }\end{array}$ & $\begin{array}{l}\text { Mean } \\
\text { score }\end{array}$ & $\begin{array}{l}\text { Standard } \\
\text { deviation }\end{array}$ \\
\hline Baseline & 9 & 22 & 14.43 & 3.520 \\
\hline Day 1 & 6 & 20 & 12.13 & 3.785 \\
\hline Day 2 & 4 & 19 & 10.20 & 3.537 \\
\hline Day 3 & 3 & 15 & 8.80 & 3.408 \\
\hline Day 4 & 2 & 12 & 7.17 & 3.018 \\
\hline Day 5 & 2 & 10 & 5.10 & 2.796 \\
\hline Day 6 & 0 & 7 & 2.90 & 1.900 \\
\hline Day 7 & 0 & 6 & 1.17 & 1.341 \\
\hline
\end{tabular}

The change in the scores from baseline to the end of treatment (day 7) is shown in Figure 1.

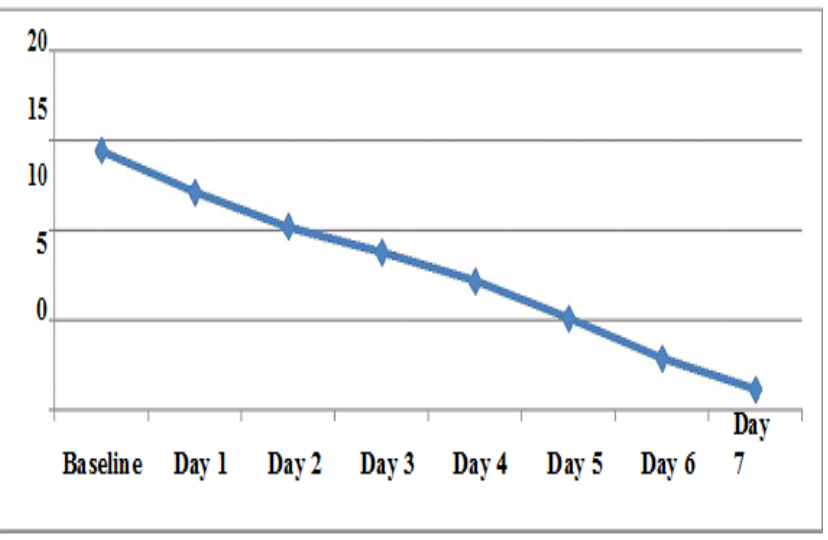

\section{Figure 1: Change in mean Rhodes Index Score from baseline to end of treatment (day 7).}

There was a statistically significant effect with the ginger extract in pregnancy induced nausea and vomiting when patients were assessed at the end of treatment (day 7; p $<0.005)$. Four patients reported symptoms of heartburn. Otherwise, there were no other reports of any adverse effects.

\section{DISCUSSION}

In our study, 30 pregnant women with nausea and vomiting were treated with ginger extract for a period of one week. They were assessed using the Rhodes Index at 
baseline as well as on all the days during the treatment period. There was a significant decrease in the mean Rhodes Index score from baseline (14.43) to end of treatment $(1.17 ; \mathrm{p}<0.05)$. There have been several studies as discussed in the section on 'Review of Literature', comparing the effects of ginger vs. placebo, vitamin B6 and other antiemetics in the management of nausea and vomiting of pregnancy. ${ }^{14-19}$ Ginger has been shown to be better than placebo in all these studies, and at least as good as vitamin B6 and other antiemetics like diphenhydramine and metoclopramide. Of the various published studies, three of them used the Rhodes Index to evaluate the efficacy of ginger. ${ }^{17}$ In our study also, we used this Index, since it is a self-administered questionnaire, which can be easily filled out by the patient, and also helps in effectively assessing the degree of nausea, vomiting and retching. Ginger seems to be well-tolerated by the woman, as well as no reports of any fetal anomalies. Four patients reported side-effects, which was heartburn in our study. There were no other adverse effects reported. Two studies comparing ginger with vitamin B6 report sedation and heartburn as the most frequent adverse effects However, there was significant difference between the two treatment groups in their incidence. ${ }^{18,19}$ It is important to note that pregnant women as such tend to suffer from heartburn because of laxity of the gastroesophageal sphincter, and somnolence because of tiredness. Therefore, these adverse effects with ginger may not be significant. The main limitations of our study are that the sample size is small, and that it is a singlearm study, with no comparator. Currently, we are recruiting patients for the placebo arm, and will be comparing the findings with that of the current study.

\section{CONCLUSION}

Ginger (Zingiber officinale) is one of the more commonly used herbal supplements for various indications. The current study showed that ginger extract is efficacious in the management of nausea and vomiting in pregnancy, similar to findings from previous literature. Although a comparative study with a known drug would be more efficient.

Funding: Indian Council of Medical Research-Short Term Studentship Program

Conflict of interest: None declared

Ethical approval: The study was approved by the Institutional Ethics Committee of CHRI, Chennai

\section{REFERENCES}

1. Miller F. Nausea and vomiting in pregnancy: the problem of perception is it really a disease? American Journal of Obstetrics and Gynecology 2002; 186(5):S182-3.

2. Woolhouse M. Complementary medicine for pregnancy complications. Australian Family Physician. 2007;35(9):695.
3. Lacasse A, Rey E, Ferreira E, Morin C, Berard A. Validity of a modified Pregnancy-Unique Quantification of Emesis and Nausea (PUQE) scoring index to assess severity of nausea and vomiting of pregnancy. American Journal of Obstetrics and Gynecology. 2008;198(1):71.e1-71.e7.

4. O'Brien B, Relyea MJ, Taerum T. Efficacy of P6 acupressure in the treatment of nausea and vomiting during pregnancy. American Journal of Obstetrics and Gynecology. 1996;174(2):708-15.

5. Zhou Q, O'Brien B, Soeken K. Rhodes Index of Nausea and Vomiting--Form 2 in pregnant women. A confirmatory factor analysis. Nursing Research. 2001;50(4):251-7.

6. Zhou Q, O'Brien B, Soeken K. Rhodes Index of Nausea and Vomiting--Form 2 in pregnant women. A confirmatory factor analysis. Nursing Research. 2001;50(4):251-7.

7. Jewell D. Nausea and vomiting in early pregnancy. American Family Physician. 2003;68(1):143-4.

8. Eliakim R, Abulafia O, Sherer DM. Hyperemesis gravidarum: a current review. American Journal of Perinatology. 2000;17(4):207-18.

9. Kousen M. Treatment of nausea and vomiting in pregnancy. American Family Physician. 1993;48(7):1279.

10. Quinlan JD, Hill DA. Nausea and vomiting of pregnancy. American Family Physician. 2003;68(1):121-8.

11. Swallow BL, Lindow SW, Masson EA, Hay DM. Development of an instrument to measure nausea and vomiting in pregnancy. Journal of Obstetrics and Gynaecology. 2002;22(5):481-5.

12. Bsat FA, Hoffman DE, Seubert DE. Comparison of three outpatient regimens in the management of nausea and vomiting in pregnancy. Journal of Perinatology. 2003;23(7):531.

13. Koch KL. Gastrointestinal factors in nausea and vomiting of pregnancy. American Journal of Obstetrics and Gynecology. 2002;186(5):S198-203.

14. Vutyavanich T, Kraisarin T, Ruangsri R. Ginger for nausea and vomiting in pregnancy: randomized, double-masked, placebo-controlled trial. Obstet Gynecol. 2001 Apr;97(4):577-82.

15. Keating A, Chez RA. Ginger syrup as an antiemetic in early pregnancy. Altern Ther Health Med. 2002 Sep-Oct;8(5):89-91.

16. Ozgoli G, Goli M, Simbar M. Effects of ginger capsules on pregnancy, nausea, and vomiting. J Altern Complement Med. 2009 Mar;15(3):243-6.

17. Willetts KE, Ekangaki A, Eden JA. Effect of a ginger extract on pregnancy-induced nausea: a randomised controlled trial. Aust N Z J Obstet Gynaecol. 2003 Apr;43(2):139-44.

18. Ding M, Leach $M$, Bradley $H$. The effectiveness and safety of ginger for pregnancy-induced nausea and vomiting: a systematic review. Women Birth. 2013 Mar;26(1):e26-30. 
19. Rhodes VA, Watson PM, Johnson MH. Development of a reliable and valid measure for nausea and vomiting. Cancer Nurs. 1984;7:33-41.
Cite this article as: Dass AP, Deodurg P, Sandhiya R. Implementing standardised rhodes index to measure the efficacy of ginger extract (Zingiber officinale) in pregnancy induced nausea and vomiting. Int J Basic Clin Pharmacol 2017;6:1932-6. 